\title{
INTELIGÊNCIA COLETIVA E INTERNET: A CULTURA DO FAÇA VOCÊ MESMO NO CONTEXTO DO LIVRO DIGITAL
}

\author{
Jitana Sara da Cunha Cardins ${ }^{1}$ \\ Marcos Antônio Nicolau ${ }^{2}$
}

\begin{abstract}
Resumo
Há pouco mais de duas décadas, sob a égide dos Meios de Comunicação de Massa, não nos era possível realizar atividades como o compartilhamento de informações, ideias e opiniões através dos canais de comunicação tradicionais, até que a comunicação em rede efetivou-se como uma realidade premente da sociedade da informação e a cibercultura trouxe consigo a possibilidade de instauração da inteligência coletiva. Nesse contexto vimos surgir uma cultura do faça você mesmo na internet, a partir da apropriação midiática por parte de todos nós internautas. São muitos os exemplos dessa prática, como no caso dos livros digitais, que dependem da livre iniciativa dos próprios usuários, transformados em autores. O presente artigo tem o propósito de analisar essa cultura do faça você mesmo e suas implicações no novo mercado editorial que se avizinha.
\end{abstract}

Palavras-chave: Ciberespaço, inteligência coletiva, faça você mesmo, livro digital.

\begin{abstract}
Over two decades ago, under the auspices of the Mass Media, we were unable to perform activities such as sharing information, ideas and opinions through traditional communication channels, until network communication was accomplished as a pressing reality of the information society, and cyberspace had brought the possibility of the introduction of collective intelligence. In this context we have seen emerge a culture of do it yourself on the internet, from the moment internet users acquired ownership. There are many examples of this practice, as in the case of digital books, which depend on the free initiative of the users themselves, transforming them into perpetrators. This article aims to analyze the culture of do it yourself and its implications in the new publishing market.
\end{abstract}

Keywords: Cyberspace, collective intelligence, do it yourself, digital book.

\section{Introdução}

A internet não é apenas um lugar de interconexão de computadores que permitem as pessoas estarem conectadas para compartilhar informações. Mais do que isso, é um ambiente de interconexão da inteligência humana, no qual os internautas podem criar, produzir e expressar suas ideias, a partir de suas próprias experiências midiáticas.

Esse potencial de autonomia comunicacional veio sendo preconizado por diversos estudiosos, a exemplo de Castells (2003), ao afirmar que se a nossa prática é baseada na comunicação e a internet modifica a maneira como nos comunicamos, então nossas experiências de vida são influenciadas por essa tecnologia da comunicação. $\mathrm{O}$ autor ainda foi mais além, ao dizer que, ao utilizarmos a essa tecnologia de variadas formas, acabamos por transformar a própria internet.

\footnotetext{
${ }^{1}$ Jornalista (Universidade Estadual da Paraíba), mestranda em Comunicação (Universidade Federal da Paraíba).

2 Jornalista, doutor em Letras (Universidade Federal da Paraíba), pós-doutor em Comunicação (Universidade Federal do Rio de Janeiro), professor do Programa de Pós-Graduação em Comunicação da UFPB.
} 
Essa condição demonstra que precisamos compreender duas importantes dimensões que se entrelaçam nesse contexto: a possibilidade de instauração de uma inteligência coletiva, como já foi preconizada por Lévy (2004), e da prática cada vez mais premente de uma cultura do faça você mesmo, tratada aqui a partir das questões de Lemos (2005).

Mas, como a cultura do faça você mesmo é muito ampla e envolve uma grande diversidade de áreas, nos concentramos no fenômeno relativamente recente da produção e difusão do livro digital, um aparato técnico que está também nas mãos dos internautas que, de meros leitores, passaram a autores. Seus desdobramentos têm afetado o mercado editorial de diferentes maneiras.

A inteligência coletiva pode ser compreendida como uma inteligência compartilhada por todos e em diversos lugares, buscando o reconhecimento e enriquecimento mútuo das pessoas. Ela nasce através do compartilhamento de ideias, formando uma rede de comunicação e inteligência que abrange todos os conhecimentos criados e adquiridos de forma individual e apresentados em um espaço comum.

De acordo com Pierre Lévy (2010), a humanidade segue para criar um ambiente mundial no qual a inteligência é o centro de tudo. E o conhecimento, neste contexto, não pode ficar parado, mas deve ser repassado de pessoa a pessoa. A inteligência coletiva, que já foi desprezada pela sociedade, hoje ganha forças com a facilidade de compartilhamento que a internet oferece, principalmente através dos blogs, fóruns, wikis, vídeos tutoriais publicados no Youtube, apresentados com a web 2.0.

Com a pretensão de observar como o compartilhamento de ideias na internet contribui para a formação dessa inteligência coletiva, este trabalho tem o objetivo de conhecer melhor a cultura do faça você mesmo e analisar como esta pode ser considerada um fenômeno de contribuição para o crescimento da inteligência coletiva. Compreende-se aqui a cultura do faça você mesmo como uma prática que teve início a partir da insatisfação de ver o rock ser industrializado e comercializado, nos anos de 1970. Era o movimento punk, que buscava a oportunidade de fazer música independente, mas que agora ressurgiu de forma mais espontânea, abrangendo várias áreas, com a instauração das mídias digitais interativas. O faça você mesmo é tratado por André Lemos (2005), quando ele defende que existe hoje uma cibercultura punk e que ela pode ser caracterizada pelas três leis da cibercultura, estudadas por ele: reconfiguração, liberação do polo de emissão e conectividade.

Para ilustrar em que níveis a cultura do faça você mesmo está englobando várias áreas de atividades dos usuários na internet, trazemos aqui o exemplo dos livros digitais, ou ebooks 
(abreviação de eletronic books). Os livros digitais surgiram no início dos anos 1970, no entanto eles estão tomando muito mais forças nos dias atuais. Com o advento das novas tecnologias e suas influências em grande parte da vida das pessoas, surgiu o interesse de inovar a forma de publicações de livros. Esse é um formato que traz grandes benefícios pelo fato de ser de baixo custo. Com o tempo, o livro digital se tornou uma forma de se ter um livro publicado sem que fosse necessário recorrer às editoras. Dessa maneira, surge uma nova oportunidade de criação de produtos independentes, fazendo crescer a cultura do faça você mesmo.

Para tanto, pretende-se inicialmente fazer uma explicação dos conceitos de cibercultura e ciberespaço, percebendo como a inteligência coletiva tem sido potencializada nesse contexto. Em um segundo momento, discutimos o conceito de inteligência coletiva e como ela vem se comportando na atualidade. Em seguida, faremos um breve estudo sobre a cultura do faça você mesmo e cibercultura punk, analisando de que forma elas podem estar presentes no contexto do crescimento da inteligência coletiva. Por fim, observamos como a cultura do faça você mesmo tem se manifestado em meio ao contexto dos livros digitais e as mudanças que isso tem ocasionado no mercado editorial da atualidade.

\section{Ciberespaço e cibercultura: espaço potencializador da inteligência coletiva}

Com o advento das novas tecnologias e a evolução dos meios de comunicação, as sociedades estão cada vez mais focadas em se atualizar e adentrar no mundo da cibercultura. De acordo com Pierre Lévy (2010, p. 17), a cibercultura é definida como “o conjunto de técnicas (materiais e intelectuais), de práticas, de atitudes, de modos de pensamentos e de valores que se desenvolvem juntamente com o crescimento do ciberespaço" e fornece à inteligência coletiva um ambiente propício para que ela se desenvolva. É na internet que ela toma força hoje e atinge graus de abrangência cada vez mais elevados. Cada pedaço de sabedoria espalhado pela web representa uma contribuição para a continuidade da formação da imensa inteligência coletiva.

Com o passar do tempo, torna-se mais fácil divulgar um pensamento, uma ideia, um conhecimento, ou uma opinião, através das ferramentas que a internet oferece. As pessoas aproveitam as oportunidades criadas com estas facilidades e buscam se fazer ouvir, dando oportunidade para o surgimento de um novo pensamento crítico em relação a nossa sociedade. O ciberespaço, definido por Lévy (2010, p. 17) como o "novo meio de comunicação que surge da interconexão mundial de computadores; um universo oceânico de informações que a internet abriga", abre-se para que os internautas publiquem suas informações e procurem se manter informados, buscando estes conteúdos da maneira que mais lhes convêm. 
A cada dia o ciberespaço fica mais abrangente e presente no cotidiano das pessoas, modificando as formas tradicionais de ensino e aprendizagem a partir do conteúdo disponibilizado principalmente nas mídias digitais. É algo vivo e marcante na atualidade, relevador para a comunicação. A inteligência coletiva manifesta-se com mais força em meio aos sites e blogs, dos mais diferenciados tipos, incluindo aqueles que disponibilizam vídeos, tutoriais, sistemas de perguntas e respostas, fóruns e portais, que fazem parte dos dispositivos digitais e destacam-se por seus mecanismos de estruturação, especificidades de linguagem, interface e tecnologias.

Nos últimos tempos o ciberespaço tem crescido ainda mais, englobando práticas e costumes no mundo inteiro. À medida que cresce fornece um espaço cada vez mais propício para que a inteligência coletiva se desenvolva. De acordo com Lévy,

nos casos em que processos de inteligência coletiva desenvolvem-se de forma eficaz graças ao ciberespaço, um de seus principais efeitos é o de acelerar cada vez mais o ritmo da alteração tecnossocial, o que torna ainda mais necessária a participação ativa na cibercultura, se não quisermos ficar para trás, e tende a excluir de maneira mais radical ainda aqueles que não entraram no ciclo positivo da alteração, de sua compreensão e apropriação (2010, p. 30).

O autor afirma, ainda, que a sociedade está cada vez mais inserida no contexto da cibercultura, dessa forma tendo que se esforçar para se manter dentro desse grande universo de informações para não ficar desatualizada. É aí que começamos a perceber que a cibercultura já entrou no cotidiano das sociedades de uma forma irreversível. Foi pensando assim que o sociólogo japonês Yoneji Masuda afirmou:

\footnotetext{
As novas tecnologias poderão mudar profundamente a qualidade da vida humana e criar uma sociedade baseada no conhecimento e na inteligência. Nesse estágio, a sociedade da informação alcançará um nível equivalente ao estágio de consumo de massa em que as pessoas possuem bens duráveis, como televisores e automóveis (MASUDA apud SIQUEIRA, 2007).
}

No momento em que o sociólogo cita uma sociedade baseada no conhecimento e na inteligência, podemos fazer uma ligação com a sociedade à qual Lévy se refere, onde a inteligência é o centro de tudo, onde o conhecimento não fica parado, onde a inteligência coletiva comanda, mobiliza habilidades, instiga pensamentos e incentiva a divulgação de todo esse material.

\section{Inteligência coletiva: a onipresença do saber}


A inteligência coletiva, teoria bastante difundida por Pierre Lévy, define tudo aquilo que envolve as capacidades cognitivas, técnicas, habilidades e conhecimentos de todos os seres humanos individualmente, mas que unidos formam uma grande rede de informações. De acordo com suas afirmações, ela é uma inteligência compartilhada em todos os lugares, avaliada constantemente, coordenada em tempo real, que conduz a uma mobilização efetiva das habilidades. $\mathrm{O}$ autor parte do pressuposto de que ninguém sabe tudo, todo mundo sabe algo, e o conhecimento, de uma forma geral, está na humanidade.

O conhecimento de cada um é a matéria-prima para a formação da inteligência coletiva. De acordo com Patrick Charaudeau (2010, p.33), informação "é a transmissão de um saber, com a ajuda de uma determinada linguagem, por alguém que o possui a alguém que se presume não possuí-lo". Dessa forma, um conhecimento é passado de pessoa para pessoa a fim de que faça parte de um conjunto de informações.

Até mesmo nos lugares onde as pessoas são tidas como "ignorantes" existe a inteligência coletiva. "A luz do espírito brilha bem ali onde se trata de fazer crer que não tem inteligência: 'fracasso escolar', 'simples execução', 'subdesenvolvimento', etc. [...] A inteligência coletiva só começa com a cultura e aumenta com ela."3 (LÉVY, 2000, p.20, tradução nossa). De acordo com Santos (2006, p. 22), cultura

está muito associada a estudo, educação, formação escolar. Por vezes se fala de cultura para se referir unicamente às manifestações artísticas, como o teatro, a música, a pintura, a escultura. Outras vezes, ao se falar na cultura da nossa época ela é quase identificada com os meios de comunicação de massa, tais como o rádio, o cinema a televisão. A lista pode ser ampliada. [...] Cultura diz respeito a tudo aquilo que caracteriza a existência social de um povo ou nação, ou então de grupos no interior de uma sociedade.

Para se ter cultura não é necessário que se tenha instrução, mas sim criatividade e conhecimentos passados hereditariamente, por isso é tão fácil encontrar os mais variados tipos de habilidades e tradições coletivas em meio às pessoas que vivem em sociedade.

O fundamento e o objetivo da inteligência coletiva são o reconhecimento e o enriquecimento mútuo das pessoas. É buscar fazer com que todos tenham oportunidade de fazer seus conhecimentos serem divulgados, sendo reconhecidos por isso, e ao mesmo tempo saber de coisas novas, absorver novas habilidades.

\footnotetext{
3 "La luz del espíritu brilla incluso allí donde se trata de hacer creer que no hay inteligencia: "fracaso escolar", "simple ejecución", "subdesarrollo", etcétera. [...]La inteligencia colectiva solo comienza con la cultura y aumenta con ella."
} 
$\mathrm{Na}$ era do conhecimento, não reconhecer o outro em sua inteligência é negar sua verdadeira identidade social, é alimentar seu ressentimento e sua hostilidade, é sustentar a humilhação, a frustração nascida da violência. Contudo, quando se valoriza o outro, segundo a gama variada de seus conhecimentos, permite a ele identificar-se de um modo novo e positivo, ajuda a mobilizá-lo, a desenvolvê-lo, a mudar sentimentos de reconhecimento que facilitarão, como reação, a implicação subjetiva de outras pessoas em projetos coletivos (LÉVY, 2000, p. 21, tradução nossa) ${ }^{4}$.

Quando se pensa em inteligência coletiva, pode-se remeter ao pensamento com diferentes idiomas, com tecnologias cognitivas, mas a inteligência culturalmente informada não é programada. Por transmissão, invenção ou esquecimento, o patrimônio comum passa a ser de responsabilidade de todos. "A inteligência do conjunto já não é resultado mecânico de atos cegos e automáticos, pois aqui é o pensamento das pessoas que o perpetua, inventa e põe em movimento a sociedade"5 (LÉVY, 2000, p.22, tradução nossa).

A partir da necessidade de se fazer conhecido e de conhecer, o ser humano busca e cria novas formas de se comunicar. Foi assim com o surgimento da oralidade, da escrita, dos meios de comunicação, como a televisão, o rádio, os jornais impressos, as revistas. Contudo, em toda a história, nunca se viu a comunicação tão forte, simples e presente no cotidiano das sociedades como nos dias de hoje, com a presença da internet.

Hoje podemos notar a presença de novas modalidades de comunicação. A informação não sai mais, necessariamente, de apenas um polo de emissão, como na mídia impressa ou televisiva. $\mathrm{Na}$ internet estão sendo criados novos meios através dos quais o próprio internauta pode veicular suas informações, ajudar outras pessoas, divulgando conhecimentos próprios, adquiridos tecnicamente ou não, repassando habilidades, contribuindo dessa forma para a expansão da inteligência coletiva. Além disso, ele pode também ter uma resposta rápida sobre aquilo que ele está veiculando.

A produção de conteúdo independente é considerada por Thompson (2008) uma das principais formas de analisarmos o desenvolvimento da comunicação e o seu impacto na sociedade moderna. O uso de meios de comunicação pela população em geral implica uma nova forma de ação e de interação, através de novos tipos de relações sociais.

\footnotetext{
4 "En la edad del conocimiento, no reconocer al otro en su inteligencia, es negar su verdadera identidad social, es alimentar su resentimiento y su hostilidad, es sustentar la humillación, la frustración de la que nace la violencia. Sin embargo, cuando se valoriza al otro, según la gama variada de sus conocimientos se le permite identificarse de un modo nuevo y positivo, se contribuye a movilizarlo, a desarrollar en él, en cambio, sentimientos de reconocimiento que facilitarán como reacción, la implicación subjetiva de otras personas en proyectos colectivos."

5 “La inteligencia del conjunto ya no es el resultado mecánico de actos ciegos y automáticos, pues aquí es el pensamiento de las personas lo que perpetua, inventa y pone en movimiento el de la sociedad."
} 
Se compreendermos a verdadeira globalização, através das considerações de Thompson (2008), como um processo de relações que acontecem em uma arena global e suas atividades envolvendo reciprocidade e interdependência de conteúdo, a web 2.0, seus blogs, fóruns e wikis etc., serão uma unanimidade neste processo e um elemento relevante no desenvolvimento das sociedades modernas e no processo de formação de um indivíduo mais reflexivo.

\section{Da inteligência coletiva na internet: cultura do faça você mesmo e a cibercultura punk}

A filosofia do faça você mesmo surgiu na década de 1970, quando bandas dos Estados Unidos começaram um movimento gerado pela insatisfação de ver o rock ser industrializado e comercializado. Era o movimento punk, que buscava a oportunidade de fazer música independente e com uma ideologia política muito forte. "As bandas punks tradicionalmente se ajudavam conseguindo shows em outras cidades, organizando turnês, lançando discos, etc." (O'HARA, 2005, p. 152).

Foi aí que surgiram as bandas com músicas com um estilo mais simples e rebelde, indo contra o que era tradicional na época. "O punk rock diferiu do rock'n'roll tradicional não apenas no som, no conteúdo das letras e no estilo de se apresentar, mas também na maneira como as bandas dirigem seus negócios e interagem com seu público" (O’HARA, 2005, p.152). O faça você mesmo tornou-se então uma forma de negócio entre os membros das bandas punks. "O espírito do empreendimento punk tem sido o faça você mesmo. Essa é uma extensão dos princípios anarquistas que requerem responsabilidade e cooperação para construir um futuro mais produtivo, criativo e agradável" (O’HARA, 2005, p.162).

Ao longo dos anos a filosofia do faça você mesmo tem se modificado e encontrado uma diversidade maior de áreas de atuação, mas sempre baseada em muita criatividade e compartilhamento de informações. Hoje em dia, podemos enxergar essa filosofia tomando força no ciberespaço. De acordo com André Lemos (2005), a cultura eletrônica contemporânea vem herdando as características dessa filosofia. “'Remixada’ e atualizada, a cibercultura se apropria, à sua maneira, do lema punk. Agora, a máxima é 'a informação quer ser livre', 'distribua, reutilize, misture conteúdo', 'crie, edite e divulgue informações”” (LEMOS, 2005).

Lemos (2005) afirma ainda que o faça você mesmo pode ser traduzido pelas três leis da cibercultura, criadas por ele mesmo. A primeira delas é a lei da liberação do polo de emissão, que é uma das principais características dessa cultura, a de produzir e distribuir informação sem a necessidade de um editor. A segunda lei é o princípio da conexão, pois, segundo ele, não basta produzir; a informação também precisa circular. “A máxima punk torna-se aqui: 'compartilhe, 
misture (remix), colabore, distribua informação'. É o “tudo em rede"; a conexão generalizada em todos os lugares e de homens, máquinas e objetos entre si” (LEMOS, 2005).

A partir do fato de que todos os produtos da era da informação passam por uma reconfiguração da cultura, Lemos (2005) afirma que é essa a terceira lei: reconfiguração de práticas sociais, instituições e modalidades midiáticas, justamente pelo fato de que cada um dá a sua parcela para modificar a cultura vigente. Ele afirma ainda que essa modificação não é aniquilação nem simples substituição, mas vem organizar e fazer vários formatos midiáticos conviverem, como o jornal online e impresso, espaço urbano e redes, podcasts e rádio, TV e web, amigos de bar e de MSN.

\footnotetext{
A emissão generalizada (primeira lei), distribuída em rede (segunda lei), cria novos formatos e modificam outros, alterando a cultura - novas formas de consumo de bens culturais, novas formatos de produção de bens simbólicos, novas visões sobre propriedade e autoria, personalização e massificação (LEMOS, 2005). ${ }^{6}$
}

O autor ainda fala sobre a questão que o movimento punk em si não existe mais nos dias de hoje como era antigamente, mas que a filosofia que formou uma cultura deixou heranças que são apropriadas pelas novas tecnologias atualmente. Lemos (2005) também cita vários exemplos da manifestação dessa herança, que toma como base as três leis da cibercultura, dentre eles os podcasts, redes $\mathrm{p} 2 \mathrm{p}$ e software livre e blogs.

\section{O livro digital como exemplo do faça você mesmo e as mudanças que provoca na atualidade}

Compartilhar informações sempre foi algo inerente à humanidade. Seja um conhecimento, uma experiência, uma habilidade, ou até mesmo uma história, o ser humano sempre sente a necessidade de compartilhar. Com a invenção da escrita, executar esse compartilhamento se tornou mais fácil, já que aquelas informações estariam gravadas e poderiam ser vistas por gerações e gerações à frente. Com o tempo foi sendo sentida a necessidade de viabilizar esses registros. A partir da criação da prensa de tipos móveis, pelo alemão Johannes Gutenberg, no século XV, a reprodução da escrita se tornou muito mais viável, passando a ser feita em larga escala, e o livro se tornou um importante produto comercial.

Desde então, o livro tem sido de grande importância para as sociedades como forma de registrar a história, a arte, a cultura, etc. "Com Gutenberg, que inventou a impressão gráfica com os tipos móveis (século XV), fixou-se de maneira definitiva a forma escrita, e as ideias e

\footnotetext{
${ }^{6}$ Disponível em: <http://revistacult.uol.com.br/home/2010/03/cibercultura-punk/> Acesso em: 25/07/2012.
} 
suas diversas expressões puderam finalmente, e aceleradamente, atingir divulgação em escala industrial" (GANDELMAN, 2007, p. 26).

À medida que o tempo foi passando e com a evolução das novas tecnologias, o digital invadiu o cotidiano das pessoas. A internet está presente em quase todas as situações e vem modificando a forma de vida das sociedades da atualidade. Com isso, todas as mídias vêm se renovando com essas mudanças. Como afirma Lemos (2011), o livro é, desde sempre, uma mídia móvel, para poder lê-lo não precisa estar fixo em lugar algum. Ele é aquele velho companheiro que pode ir a qualquer lugar. Como forma de adaptação na era da cibercultura, surgiram os livros digitais, ou ebooks, que são publicações disponíveis em formato digital e vêm possibilitando uma nova forma de leitura.

Os livros digitais surgiram no início dos anos de 1970, quando Michael Hart disponibilizava ebooks online em formato txt. através do Projeto Gutenberg ${ }^{7}$, que visava a distribuição gratuita de livros eletrônicos.

\begin{abstract}
Mas somente por volta de 1998 são lançados os primeiros dispositivos ou softwares de leitura digital: os e-books reader devices. Tais aparelhos permitem a leitura desses livros numa tela plana de cristal líquido colorido, portátil e com grande capacidade de armazenamento. $\mathrm{O}$ aparelho possui funcionalidades como paginação, mudança de orientação de página, marcação de página, destaque de texto, anotações do leitor, busca por texto, além de luz interna para leitura no escuro. A maioria desses recursos não pode ser usada no exemplar de papel, o que confere outra vantagem ao livro digital (MESQUITA; CONDE, 2008, p.3).
\end{abstract}

Além de todas essas facilidades, tem uma que chama atenção: o baixo custo da publicação. A partir disso, algo de novo é proporcionado para os usuários. Eles não precisam mais passar por uma editora para poder publicar um livro, eles podem fazer isso por eles mesmos. O usuário, agora, passou a ter acesso à produção do livro, bem como ao seu compartilhamento. Para tanto, os novos aparatos tecnológicos que instauraram a web estão disponibilizando aplicativos e recursos midiáticos diversos para uma cultura do faça você mesmo nesse contexto.

Os livros digitais permitem aos autores independentes a publicação de suas obras com valor acessível - podendo até ser de graça, caso o próprio autor faça a edição e diagramação em formato digital - e com um alcance enorme, pois estaria disponível para download na Internet (VIRGINIO; NICOLAU, 2012, p. 5).

Existem vários sites que possibilitam a publicação de livros digitais com várias opções de pacotes, desde a simples publicação do livro com a diagramação da capa até com campanha

\footnotetext{
${ }^{7}$ Disponível em: http://www.promo.net/pg/. Acesso em: 27/07/2012.
} 
para promoção e divulgação do livro e autor. Um deles é o Buqui Livros Digitais ${ }^{8}$, que oferece pacotes com valores que variam entre $\mathrm{R} \$ 790,00$ e $\mathrm{R} \$ 12.900,00$.

Figura 1: Pacotes para produção de livros digitais oferecidos pelo site Buqui Livros

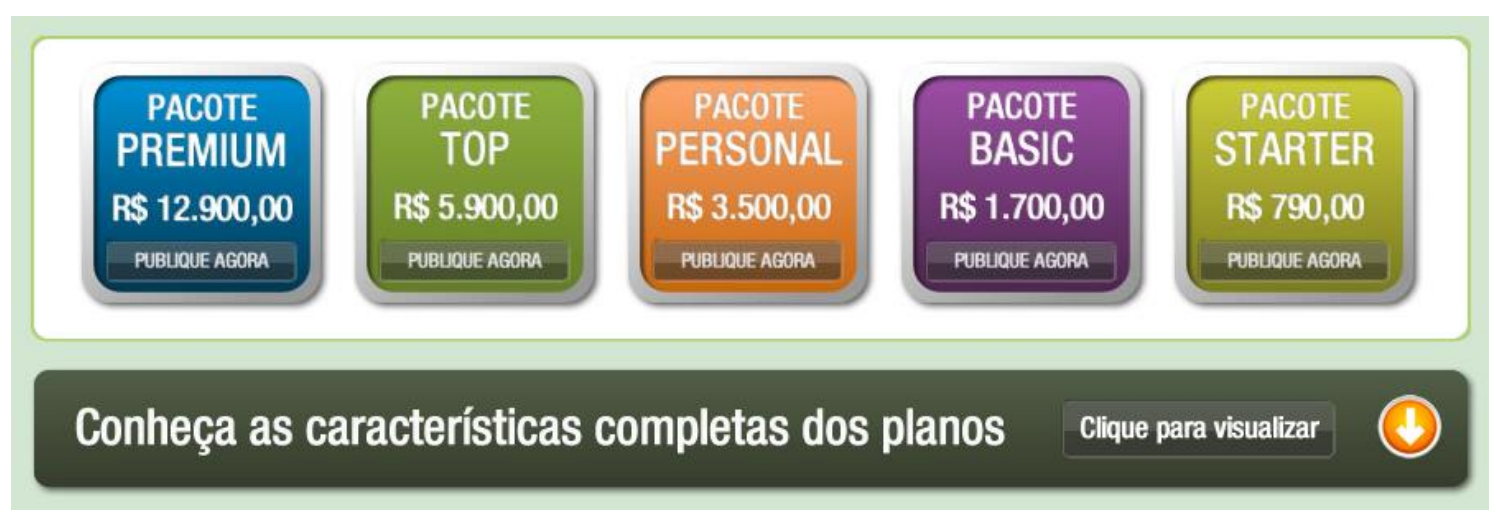

Fonte:

http://www.buqui.com.br/site/default.asp?TroncoID=929090\&SecaoID $=548108 \&$ SubsecaoID $=0$

O mercado de livros digitais ainda está chegando ao Brasil. De acordo com pesquisa feita em 2011 pelo Instituto Pró-Livro, apenas 5\% dos entrevistados dizem já ter lido um livro digital, e 70\% afirmam nunca ter ouvido falar sobre os ebooks. Essa é uma realidade que parece ser distante em nosso país, mas já está se consolidando nos Estados Unidos e na Europa. Na livraria virtual Amazon, empresa norte-americana, os ebooks já são mais vendidos do que os livros impressos, além de ser vendido também o seu próprio leitor digital, o Kindle.

A partir disso podemos perceber que está sendo criada uma nova modalidade mercadológica. Estão sendo criados e vendidos softwares e aplicativos para essa nova forma de publicação, e qualquer pessoa pode fazer uso dessas novas possibilidades.

O leitor é editor e distribuidor. Nova forma de leitura onde a ação de edição e compartilhamento pode ser feita pelo leitor. Crescem formas e instrumentos de uma cultura letrada que se faz por uma leitura sociabilizada. O leitor é também "tipógrafo", que pode mexer nas fontes e alterar as localizações das informações. Só há textos e leitores móveis (LEMOS, 2011).

É nesse ponto que percebemos como o usuário está fazendo uso da cultura do faça você mesmo, no momento em que cada vez mais livros são criados pelos próprios autores, sem que haja necessidade de passar por uma edição. Essas pessoas estão inseridas em um contexto de liberação do polo de emissão, pelo fato de estarem livres para expressar suas ideias, opiniões, habilidades, etc.; estão participando também de um momento de reconfiguração das práticas

\footnotetext{
${ }^{8}$ Disponível em: <http://www.buqui.com.br> Acesso em: 16/04/2013.
} 
editoriais dos livros, já que os livros de papel não deixaram de existir ao passo que os eletrônicos vêm ganhando seu espaço; além de estarem também conectadas à internet, demonstrando assim que esse é um fenômeno que está de acordo com as três leis da cibercultura, de Lemos (2005).

O livro digital, com suas novas configurações, se torna mais uma mídia de grande importância para a cibercultura. Entra para a lista das mídias móveis que fazem uso das novas tecnologias e que oferecem novas possibilidades de compartilhamento para um público que, antes, não tinha oportunidade de se expressar.

\section{Considerações finais}

Ao observamos a expansão da internet e a evolução das mídias digitais, consolidada pela livre conexão entre as pessoas, em permanente troca de opiniões e informações, passamos a compreender melhor como esse ambiente tornou-se propício ao compartilhamento de ideias geridas pelos próprios internautas, mesmo que por entre o gigantesco aparato mercadológico presente na rede mundial de computadores.

Em meio a tudo isso, pudemos constatar como os livros digitais, por sua vez, foram se constituindo ferramentas oportunas a esse compartilhamento. É comum observar as pessoas à procura de fazerem suas próprias publicações, escreverem, editarem e publicarem aquilo que bem entendem. E essa é a ideia da cultura do faça você mesmo: permitir às pessoas a fazerem elas mesmas suas próprias produções, sem necessariamente precisar recorrer aos custosos suportes comerciais. E não somente isso. A cultura do faça você mesmo, nesse contexto, é tão instigadora, que está provocando a criação de novas modalidades mercadológicas. Novos aparatos tecnológicos estão sendo criados e o público está fazendo uso deles, não apenas para usufruir como leitor, mas, também, como criador.

Embora os preconizadores da inteligência coletiva a tenham colocado como utopia, percebemos que atividades como essas, incentivadas pela cultura do faça você mesmo, parece representar essa força espontânea de conexão de inteligências humanas, em busca de livre expressão e autonomia comunicacional: um princípio da prática que pode vir a ser a expressão da verdadeira inteligência coletiva.

Estamos vivenciando um importante período de transição social e cultural na história da humanidade, em que um processo de midiatização está em curso e a prática do compartilhamento das produções pessoais está apenas começando. E, diante das poderosas forças econômicas que sustêm a internet, precisamos impor o direito à negociação: podemos ser consumidores se também pudermos ser produtores. 
Como disse Barbrook (2009), chegamos ao fim do milênio constatando que as pessoas tomaram o controle das tecnologias da informação a fim de melhorar suas existências. E, liberadas de um futuro pré-determinado por McLuhan, sentiram-se inspiradas a construir um novo caminho:

\begin{abstract}
Criatividade cooperativa e democracia participativa devem ser estendidas do mundo virtual para todas as áreas da vida. Desta vez, o novo estágio de crescimento deve ser uma nova civilização. Mais do que disciplinar o presente, essas novas visões futuristas podem ser abertas e flexíveis. Nós somos os inventores de nossas próprias tecnologias. Nós podemos controlar nossas próprias máquinas. Nós somos os criadores das formas de coisas que virão. Nós podemos intervir na história para realizar nossos próprios interesses. Nossas utopias fornecem a direção para o caminho do progresso humano (BARBROOK, 2009, p. 383-384).
\end{abstract}

É a partir dessa força pessoal da cultura do faça você mesmo que podemos projetar um vetor de interesses coletivos para que, cada vez mais, as novas tecnologias sejam projetadas para servirem aos interesses sociais, consolidando de vez a democracia digital que se prenuncia.

(Recebido em 15/07/2013, aprovado em 28/07/2013)

\title{
Referências
}

BARBROOK, Richard. Futuros imaginários: das máquinas pensantes à aldeia global. São Paulo: Peirópolis, 2009.

CASTELLS, Manuel. A galáxia da internet: reflexões sobre a internet, os negócios e a sociedade. Rio de Janeiro: Jorge Zahar, 2003.

GANDELMAN, Henrique. De Gutenberg à Internet: direitos autorais das origens à era digital. 5 ed. revista e atualizada. Rio de Janeiro: Record, 2007.

LEMOS, André. Cibercultura Punk. In Revista Cult, n.96, "Dossiê Punk”, out.2005.

, André. Livro e mídia digital. <Disponível em: http://andrelemos.info/2011/10/flica/>

Acesso em: 26/07/2012.

LÉVY, Pierre. Inteligencia Colectiva: por una antropología del ciberespacio. Washington, DC: Organización Panamericana de la Salud, 2004.

Cibercultura. 3 ed. São Paulo: 34, 2010.

LIMA, Cristina. Os livros digitais na pesquisa 'Retratos da leitura no Brasil'. Disponível em: http://www.nosdacomunicacao.com.br/panorama interna.asp?panorama=501\&tipo=R. Acesso em: 09/04/2012.

MESQUITA, Isabel; CONDE, Mariana. A evolução gráfica do livro e o surgimento dos ebooks. Disponível em: < http://www.intercom.org.br/papers/regionais/nordeste2008/resumos/R12-06451.pdf> Acesso em: 26/07/2012.

O’HARA, Craig. A filosofia do punk: mais que barulho. São Paulo: Radical Livros, 2005.

SANTOS, José Luiz dos. O que é cultura. São Paulo: Brasiliense, 2006. 
SHIRKY, Clay. A cultura da participação: criatividade e generosidade no mundo conectado. Rio de Janeiro: Zahar, 2011.

THOMPSON, John B. A mídia e a modernidade: uma teoria social da mídia. Petrópolis, RJ: Vozes, 2008.

VIRGINIO, Rennam; NICOLAU, Marcos. Livro Digital: Percalços e Artimanhas de um Mercado em Reconfiguração. Disponível em:

<http://www.intercom.org.br/papers/regionais/nordeste2012/resumos/R32-0794-1.pdf >

Acesso em: 16/04/2013. 